\title{
Adherent cells from rheumatoid synovia: identity of HLA-DR positive stellate cells
}

\author{
J HEINO, ${ }^{1}$ M VIANDER, ${ }^{2}$ J PELTONEN, ${ }^{1}$ AND T KOURI ${ }^{1}$
}

From the Departments of ${ }^{\prime}$ Medical Chemistry and ${ }^{2}$ Medical Microbiology, University of Turku, Turku, Finland

SUMMARY Rheumatoid synovia were enzymatically digested and the in vitro morphology of different types of plastic adherent cells was observed. Four main types of cells were found after 24 hours in culture: $(a)$ stellate cells which had nuclei resembling those of classical cultured fibroblasts, but which stained positively with $\mathrm{I}_{2}$ antibody (anti-HLA-DR antibody); (b) fibroblastic cells; $(c)$ cells which resembled morphologically in vitro macrophages and which were $I_{2}$ and OKM-1 positive; $(d)$ round monocytes. The stellate cells did not stain with anti-S-100 or OKT-6 antibodies, which are used to detect classical antigen presenting dendritic cells. Furthermore, in the presence of indomethacin the stellate shaped cells were replaced by new $\mathrm{I}_{2}$ positive cells with a typical fibroblast shape. These results support the view that the stellate cells in synovial cell cultures represent HLA-DR positive fibroblasts, probably B cells of synovial lining.

Key words: rheumatoid arthritis, synovial lining cells, synovial fibroblasts, dendritic cells HLA-DR antigens, fibronectin, synovial membrane.

Synovial tissue consists of a lining cell layer and a stroma of loose connective tissue. On electron microscopy the lining is seen to be formed by $\mathrm{A}$ and $B$ cells, representing macrophage-like and fibroblast-like cells. ${ }^{\prime}$ In rheumatoid arthritis the lining cell layer proliferates and inflammatory cells infiltrate from the circulation into the synovial tissue. $^{2}$ The stromal infiltrates usually aggregate around the capillaries but also spread diffusely through the tissue. ${ }^{3-5}$ In the nodular aggregates the most prominent cell is the helper T lymphocyte, ${ }^{34}$ usually seen in close contact with dendritic HLADR positive cells which probably take part in antigen presentation. ${ }^{34}$

In order to make closer observations possible Burmester et al released synovial cells from tissue. ${ }^{6}$ On the basis of morphology and the expression of typical surface antigens the plastic adherent population of the synovial cells was divided into subgroups: classic mononuclear phagocytes, fibroblasts, and multibranched stellate cells, the origin of which remains unknown. In cultures of synovial cells these

Accepted for publication 29 July 1986

Correspondence to Dr J Heino, Department of Medical Chemistry. University of Turku, Kiinamyllynkatu 10, SF-20520 Turku, Finland. stellate cells produce most of the collagenase, suggesting that they are fibroblasts. ${ }^{78}$ On the other hand, they are HLA-DR positive, ${ }^{69}$ which is unknown for conventional fibroblasts. Certain authors have therefore suggested that these stellate cells in culture represent the dendritic antigen presenting cells ${ }^{6}$ seen in immunohistological preparations of rheumatoid synovia. ${ }^{34}$

HLA-DR positive cells are of special interest as the HLA-DR4 tissue antigen has been detected some three- to fourfold more often among rheumatoid patients than in the normal population. ${ }^{10}$ It is $O$ probable that the class II antigens of the major histocompatibility complex have an important role in the pathogenesis of rheumatoid arthritis.

The purpose of this study was to elucidate further $\mathscr{N}$ the identity of the stellate cells in synovial cell $N$ cultures. We tested $(a)$ whether these cells express N S-100 protein or antigen detected by OKT- 6 antibodies (expressed by conventional dendritic cells), or both; (b) whether they stain with OKM-1

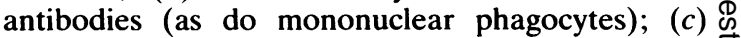
whether these cells produce fibronectin; and $(d) \stackrel{?}{?}$ whether the stellate morphology of the cells is caused by activation with prostaglandins, as de- $\mathbb{\mathbb { D }}$ scribed for fibroblasts. 


\section{Materials and methods}

\section{CELL CULTURES}

Synovial specimens were obtained from six patients with classic or definite rheumatoid arthritis undergoing orthopaedic operations. Synovial cells were released by digestion of tissue specimens with collagenase $(0.5 \mathrm{mg} / \mathrm{ml}$ collagenase type IV, No C-5138. Sigma) and DNAase $(0 \cdot 15 \mathrm{mg} / \mathrm{ml}$ DNAase type I, No 260912, Calbiochem) in Hanks's balanced salt solution containing $5 \mathrm{mM} \mathrm{CaCl}_{2}{ }^{7}$ After shaking at $37^{\circ} \mathrm{C}$ for two to three hours the cell suspension was filtered through cotton gauze and the cells collected by centrifugation. For primary cultures the cells were resuspended in Dulbecco's modification of Eagle's minimum essential medium supplemented with antibiotics (penicillin G $100 \mathrm{IU} / \mathrm{ml}$ and streptomycin sulphate $50 \mu \mathrm{g} / \mathrm{ml}$ ) and $10 \%$ fetal bovine serum (FBS). In some experiments $14 \mu \mathrm{M}$ indomethacin was also added to the culture medium. After incubation for 24 or 96 hours the cultures were washed four times with phosphate buffered saline, and the cells were fixed with $3.5 \%$ paraformaldehyde for $10 \mathrm{~min}$. To localise intracellular proteins the cells were made permeable by acetone $\left(-20^{\circ} \mathrm{C} ; 10 \mathrm{~min}\right)$ treatment. The cells used for indirect immunofluorescence were cultured on glass coverslips $13 \mathrm{~mm}$ in diameter, those for cytological staining on $9 \mathrm{~cm}^{2}$ chamber slides (Nunc, Roskilde, Denmark).
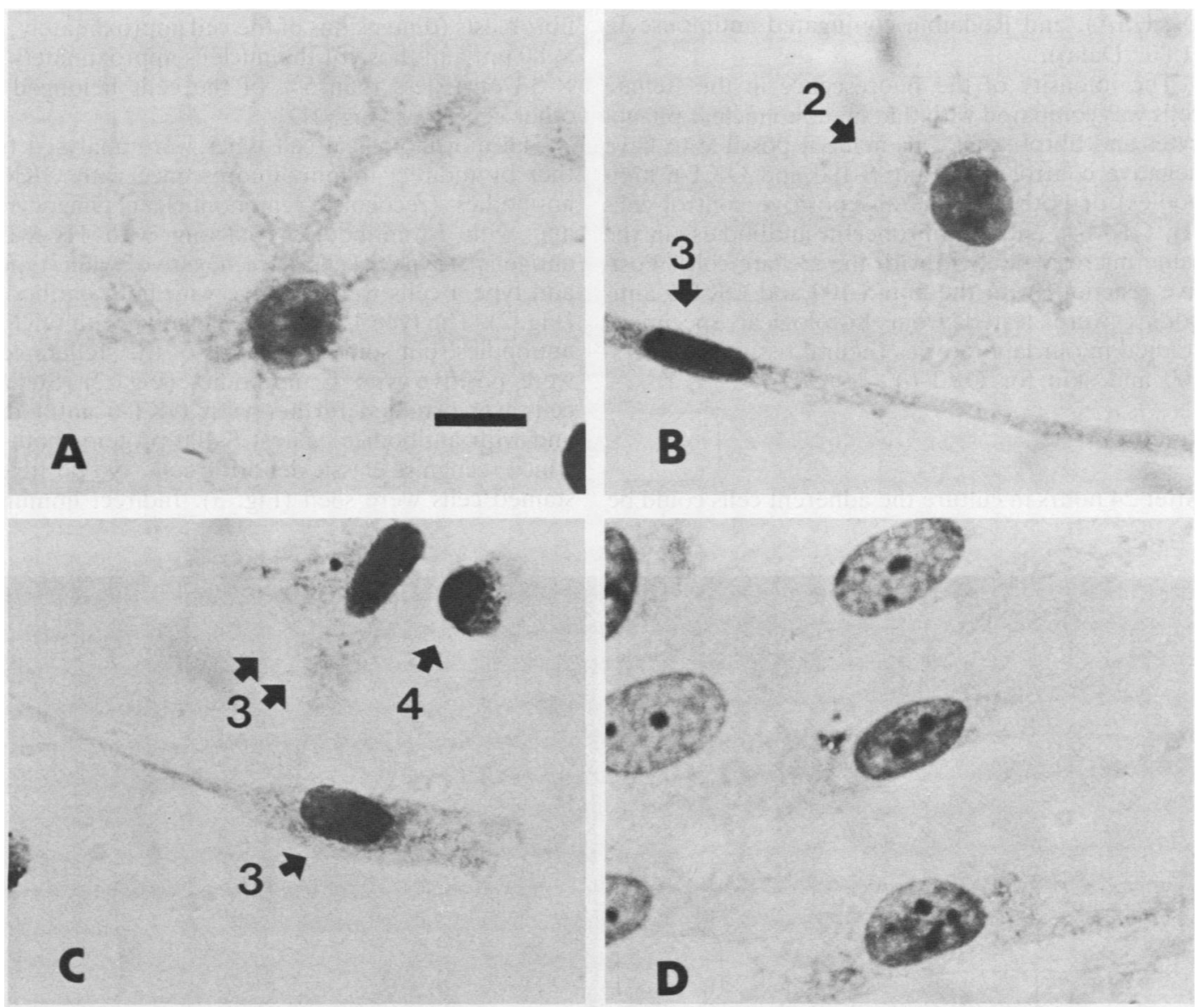

Fig. 1 May-Grünwald-Giemsa staining of different cell types from rheumatoid synovium after 24 hours in culture.

(A) Stellate cell (type I cell). (B) Fibroblast-like flattened cell (type 2 cell) and macrophage-like elongated cell (type 3 cell). (C) Macrophage-like cells: elongated and wedge shaped cell (two arrows) (both type 3 cells) and round monocyte (type 4 cell). (D) Adherent cells cultured for 96 hours. Bar $=10 \mu \mathrm{m}$. 
MORPHOLOGICAL AND

IMMUNOFLUORESCENCE STUDIES

The cell morphology was studied by haematological May-Grünwald-Giemsa (MGG) staining of methanol fixed samples. The dimensions of the cells and the nuclei were measured from microscopic photographs of MGG stained samples. Cell surface markers and fibronectin were localised by indirect immunofluorescence. The following antibodies were used: antifibronectin (1:50, Dako, Copenhagen, Denmark), anti-S-100 (1:40, Dako), $\mathrm{I}_{2}(1: 100$, Coulter Immunology, Hialeah, FL, USA), OKM-1 (1:100, Ortho Diagnostic System, Raritan, NJ, USA), and OKT-6 (1:100, Ortho). Secondary antibodies were fluorescein isothiocyanate (FITC)conjugated antirabbit IgG (1:50, Wellcome Reagents Ltd, Beckenham, UK), FITC conjugated antimouse Ig (1:100, Miles Laboratories, Elkhart, IN, USA), and Rodamin conjugated antimouse Ig (1:80, Dako).

The intensity of the fluorescence in the stellate cells was compared with that in mononuclear phagocytes and fibroblasts. This made it possible to have negative control cells (anti-S-100 and OKT-6 antibodies) or both negative and positive control cells $\left(\mathrm{I}_{2}, \mathrm{OKM}-1\right.$, and antifibronectin antibodies) in the same microscopic field with the stellate cells. Positive reactions with the anti-S-100 and OKT-6 antibodies were tested from histological specimens studied in our laboratories (neural tissue for anti-S100 and skin for OKT-6).

\section{Results}

After 24 hours in culture the adherent cells could be divided into four groups: $(a)$ stellate cells with three to six branches (length of one branch approxi- $\frac{-}{\infty}$ mately $50 \mu \mathrm{m}$, diameter of nucleus approximately $10 \mu \mathrm{m}) ;(b)$ large flattened cells (diameter of cell $\stackrel{\oplus}{\longrightarrow}$ 35-40 $\mu \mathrm{m}$, that of nucleus approximately $10 \mu \mathrm{m})$; 음 (c) elongated or wedge shaped cells (dimensions of $\overline{\underline{O}}$ an elongated cell approximately $7 \times 70 \mu \mathrm{m}$, diameter $\frac{\bar{\sigma}}{\partial}$ of nucleus 5-10 $\mu \mathrm{m})$; and (d) round monocytes $\stackrel{\curvearrowright}{\Omega}$ (diameter of cell approximately $12 \mu \mathrm{m}$, that of nucleus $6-10 \mu \mathrm{m}$ ) (Figs. $1 \mathrm{~A}-1 \mathrm{C}$ ). The estimated $\overrightarrow{0}$ percentages of different cell types were as follows: type $16-25 \%$, type $228-52 \%$, type $318-20 \%$, and $\overrightarrow{\vec{\omega}}$ type $422-27 \%$ (range of two typical experiments). The nuclei of type 1 and type 2 cells resembled those of conventional fibroblasts, with usually two or more nucleoli. The nuclei of type 3 and type 4 cells stained more intensively and had no nucleoli. After $96 \mathrm{~h}$ in culture most of the cells were conventional $\vec{A}$ fibroblasts (dimensions of the cell approximately, 13 음 $\times 80 \mu \mathrm{m}$ and those of the nucleus approximately $12=$ $\times 13 \mu \mathrm{m})$; less than $5 \%$ of the cells belonged to $T^{T}$ other cell types (Fig. 1D).

The morphological cell types were analysed fur- $\frac{C}{2}$ ther by indirect immunofluorescence with OKM-1 antibodies (recognising mononuclear phagocytes) $\vec{\bullet}$ and with $I_{2}$ antibodies (reacting with HLA-D\$ antigens). Type 2 cells were negative, while type and type 4 cells were positive with both antibodics (Fig. 2). The type 1 cells were negative with OKM-1 antibodies, but some two thirds of the stellate cells were positive with $I_{2}$ antibodies (Fig. 2). Stellate $\frac{0}{\mathbb{D}}$ cells were studied further with OKT-6 antibodies and with antibodies against S-100 protein, both of $\overrightarrow{\overline{0}}$ which recognise classic dendritic cells. No positively stained cells were seen (Fig. 3). Indirect immuno-
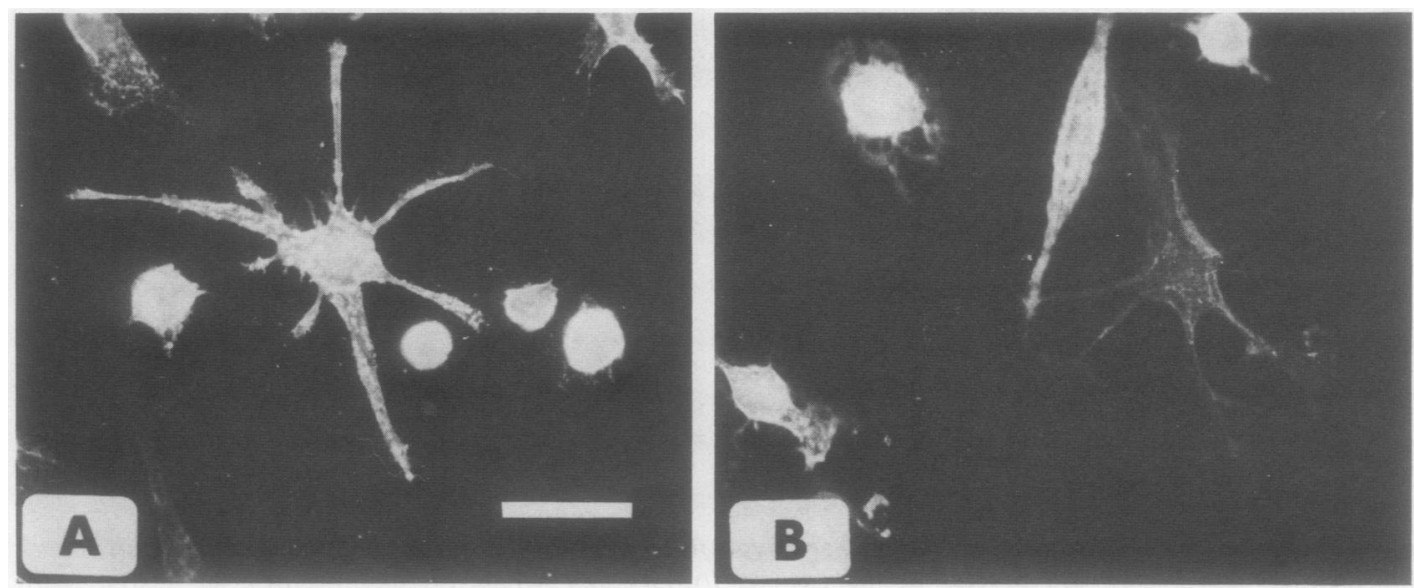

Fig. 2 Indirect immunofluorescence with $I_{2}$ antibodies recognising the $H L A-D R$ antigens. (A) $H L A-D R$ positive stellate cell. (B) $H L A-D R$ negative stellate cell and $H L A-D R$ positive monocytes and elongated macrophages. Bar $=30 \mu m$. 

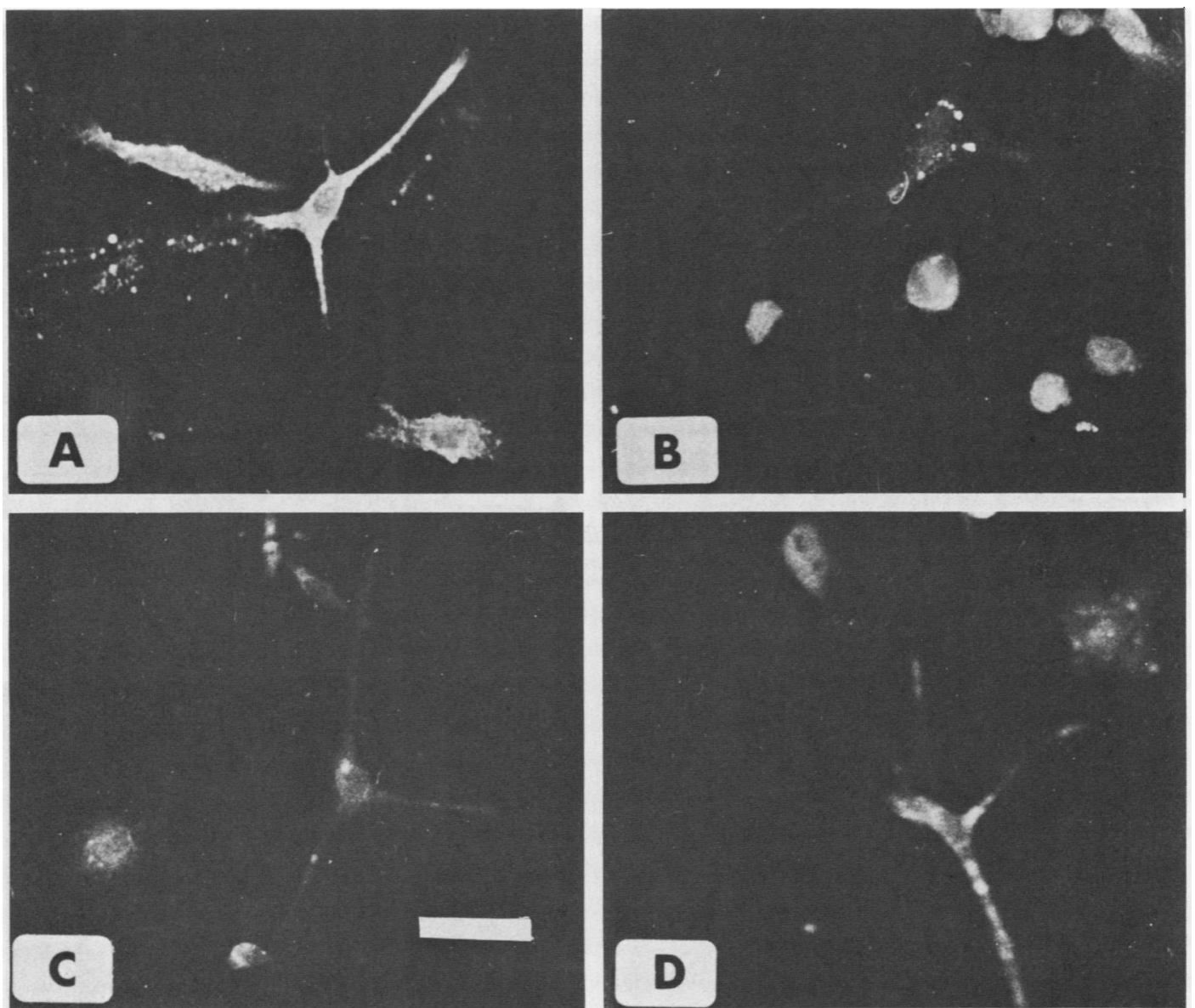

Fig. 3 Indirect immunofluorescence of the stellate cells with $(A) I_{2}$ antibodies, $(B) O K M-1$ antibodies, $(C) O K T-6$ antibodies, and $(D)$ antibodies against $S$ - 100 protein. Bar $=30 \mu \mathrm{m}$.
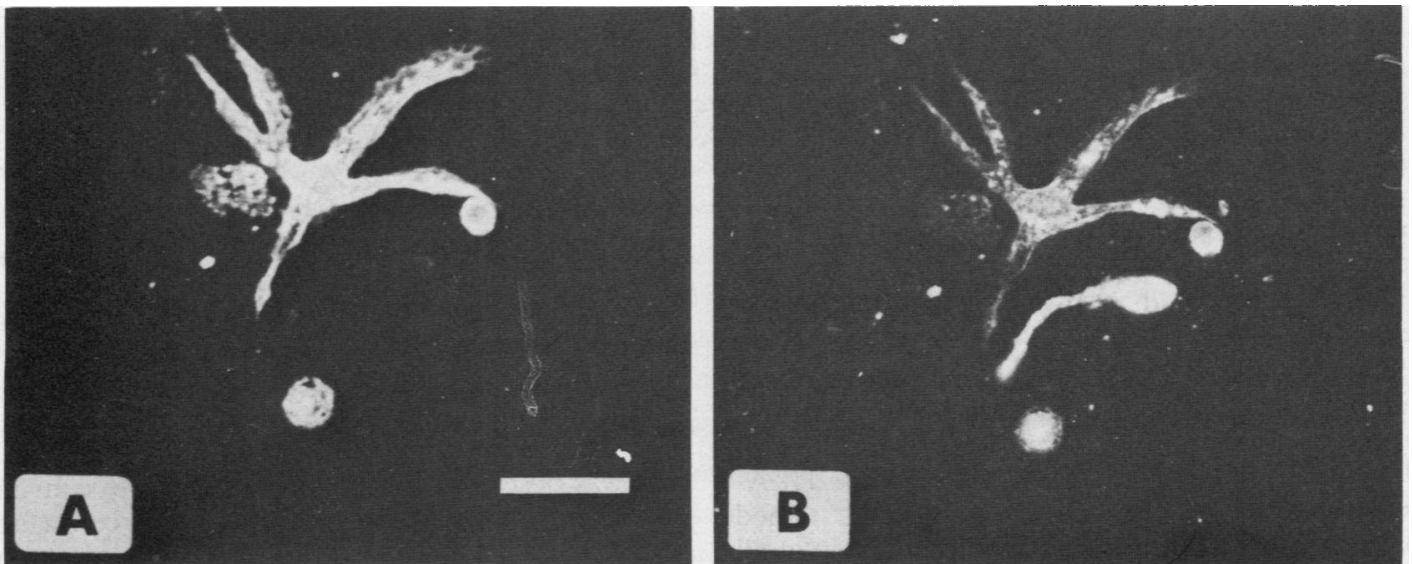

Fig. 4 Double immunofluorescence against (A) HLA-DR antigens and (B) fibronectin. Stellate cells and monocytes were $H L A-D R$ positive. HLA-DR negative cells containing fibronectin represent fibroblasts (spreading deficient because of lack of serum). Bar $=30 \mu \mathrm{m}$. 

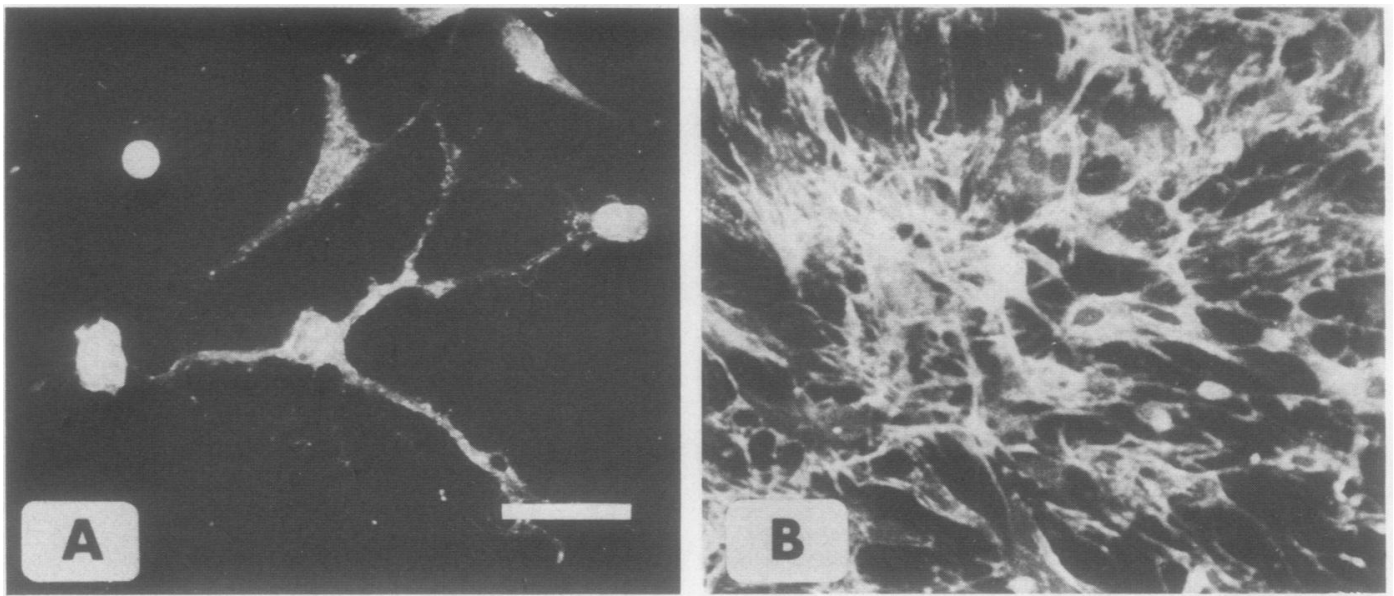

Fig. 5 Indirect immunofluorescence with antifibronectin antibodies. (A) Adherent cells from rheumatoid synovia cultured $\overrightarrow{\vec{D}}$ in the presence of fetal bovine serum for 24 hours. (B) Adherent cells from rheumatoid synovia cultured in presence of fetal bovine serum for 96 hours. Bar $=30 \mu \mathrm{m}$.
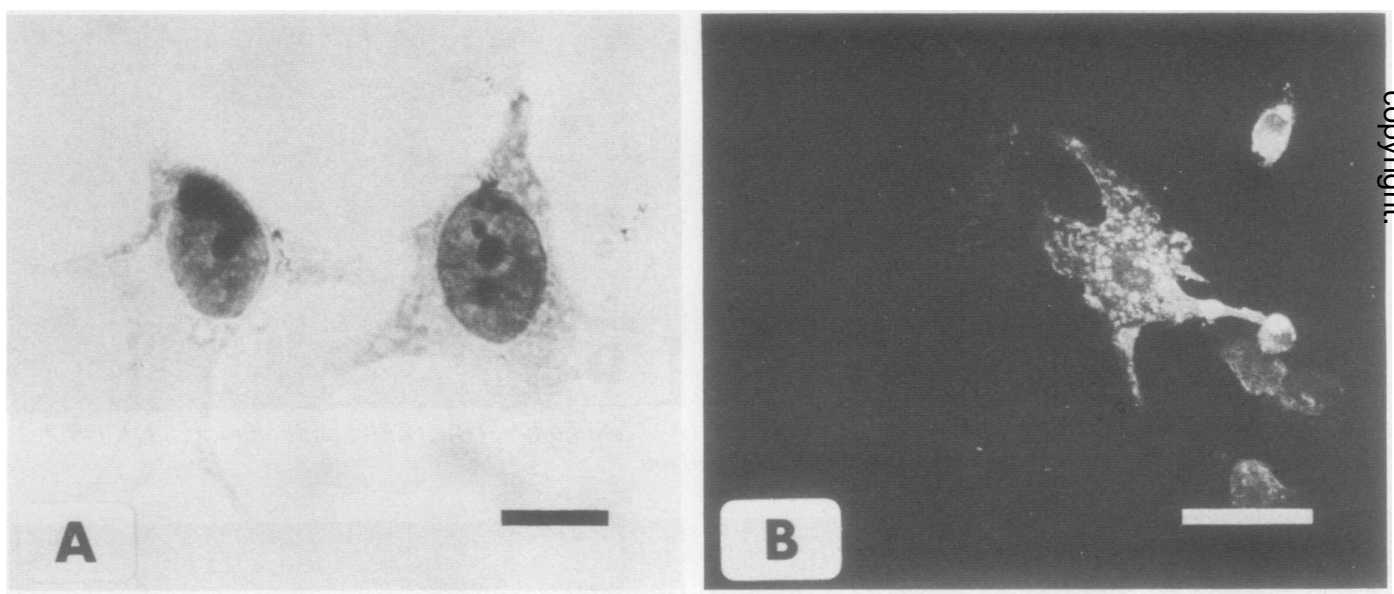

Fig. 6 Adherent cells from rheumatoid synovia cultured for 24 hours in the presence of $14 \mu \mathrm{M}$ indomethacin.

(A) May-Grünwald-Giemsa staining. Bar $=10 \mu \mathrm{m}$. (B) Indirect immunofluorescence against HLA-DR antigens. Bar $=30 \mu \mathrm{m}$.

fluorescence staining was also performed for cells after 96 hours in culture; some $I_{2}$ positive cells were still seen, identified both as macrophages and stellate cells (not shown).

Simultaneous indirect immunofluorescence staining of fibronectin and HLA-DR antigens showed that most of the fibronectin was localised in HLA-DR negative cells (type 2 cells), while HLADR positive cells, including the stellate cells, stained less intensively for fibronectin or did not stain at all (Fig. 4). When cultured in the presence of FBS all of the cells contained surface associated fibronectin (Fig. 5A). After 96 hours the cultures containing
FBS were covered by a fibronectin network (Fig. 5B).

When prostaglandin synthesis was inhibited by plating the cells onto culture dishes in then presence of indomethacin $(14 \mu \mathrm{M})$, only singleñ stellate cells (less than $1 \%$ of the total amount) were $\omega$ seen after 24 hours culturing. Instead, a new celk type was observed, much closer in shape to conven tional synovial fibroblasts than to stellate cells (Fig. 6A). This cell type had three to five broad exten sions instead of long branches. Approximately half of these cells stained positively with $\mathrm{I}_{2}$ antibodies, (Fig. 6B). 


\section{Discussion}

Adherent cells from rheumatoid synovia have previously been classified by Burmester et al into three populations ${ }^{\mathrm{t}}$ : $(a)$ cells bearing HLA-DR antigens and monocyte/macrophage markers, $(b)$ HLA-DR positive cells showing no other properties of mononuclear phagocytes, and (c) fibroblastic cells. In the present study the same main types of cells were found. Nevertheless, we found it useful to reclassify the synovial cells on a primarily morphological basis (Fig. 1). The stellate cells (our type 1 cells) were included in Burmester's second group. Our type 2 cells represent fibroblasts and type 3 and type 4 cells mononuclear phagocytes. Mononuclear phagocytes were subdivided according to their morphology into cells resembling classical monocytes (type 4) and cells resembling macrophage-like cells grown in vitro (type 3 ). ${ }^{11} 12$

The stellate cells of synovial cultures are known to be active producers of collagenase. ${ }^{78}$ They have also been reported to express HLA-DR antigens. ${ }^{69}$ It is not known, however, which cells of rheumatoid synovial tissue become stellate shaped when grown in vitro.

Because of their dendritic morphology and the expression of HLA-DR antigens, the stellate cells in synovial cell cultures have been connected with antigen presenting non-lymphoid dendritic cells, ${ }^{6}$ usually found in lymphoid follicles and in normal skin as Langerhans' cells. ${ }^{1.3}$ Rheumatoid synovial tissue contains OKT-6 positive dendritic cells. ${ }^{+}$ Among the adherent cells cultured from rheumatoid synovia, however, we found no cells positive with OKT-6 antibodies or with antibodies against another dendritic cell marker, S-100 protein ${ }^{1+15}$ (Fig. 3). These results support the view that the adherent stellate cells cultured from rheumatoid synovia do not represent classic dendritic cells. This is consistent with the finding that cell preparations containing these stellate cells are less stimulatory than periheral blood non-T cells in mixed leucocyte reactions. ${ }^{16}$

There are several reasons for considering that adherent synovial stellate cells, though HLA-DR positive, are essentially fibroblasts. With MGG staining the nuclei of the stellate cells and those of the fibroblasts resembled each other closely (Figs $1 \mathrm{~A}$ and 1B). Furthermore, Hendler et al have recently reported that at least some of the cells with stellate morphology turn into fibroblasts when cultured for some days. ${ }^{17}$ Stellate cells also produce collagenase, ${ }^{78}$ which is typical of connective tissue cells. In addition, when passaged cultures of synovial fibroblasts are cocultured in the presence of mononuclear cells, some of them become stellate- like. ${ }^{18}$ This phenomenon is caused by prostaglandin $E_{2}$ released from synovial fibroblasts which have been induced by interleukin 1 derived from mononuclear phagocytes. ${ }^{19} 20$

The stellate morphology of the cells in primary cultures may also be caused by prostaglandins since in this study stellate cells were not evident in cultures when indomethacin was present. The HLADR positive cells seen instead of the stellate cells resembled fibroblasts in morphological structure (Fig. 6). Although fibroblasts are usually HLA-DR negative, they may express HLA-DR antigens when induced by interferon $\gamma .{ }^{21} 22$

In long term cultures both fibroblasts ${ }^{23}$ and macrophages $^{24}$ synthesise fibronectin. It is well documented, however, that in situ in the synovial lining type B cells, but not type A cells, can synthesise this glycoprotein. ${ }^{25} 26$ It has also been suggested that, when observed by immunoelectron microscopy, both type A and type B cells may appear to contain HLA-DR antigens. ${ }^{27} \mathrm{We}$ were therefore interested in the question of whether our stellate cells contain fibronectin in short term $(24 \mathrm{~h})$ cultures, as this would suggest a type B cell character. In serum free cultures, fibronectin was mainly located in HLA-DR negative cells (conventional fibroblasts), while the stellate cells lacked fibronectin. This problem is more complicated, however, because in the presence of serum all types of cells contained fibronectin (Fig. 5). This can mean that the synthesis of fibronectin by stellate cells is more serum dependent than that of conventional fibroblasts - of course, adherence of external fibronectin onto the cells from the serum is another possibility. Further experiments are needed before final conclusions can be made.

Our previous observation was that interleukin 1 and prostaglandin $E_{2}$ can induce the disappearance of the fibronectin network in passaged cultures of synovial fibroblasts. ${ }^{21}$ Similarly, the fibronectin network was here formed in the primary cultures when most of the cells potentially capable of producing interleukin 1 had disappeared (Fig. 5).

It is probable that the HLA-DR positive stellate cells in cultures of adherent cells from rheumatoid synovia represent fibroblasts, perhaps type B cells of the synovial lining layer. Further investigation is needed, especially concerning the ability of the stellate cells to produce connective tissue components, before a definitive answer to this question is possible.

We wish to thank Dr Sakari Einola for rheumatoid synovial samples and Mrs Liisa Peltonen for expert technical assistance. This work was supported financially by institutional grants from the Academy of Finland and from the Sigrid Jusclius Foundation and by a grant to the author (JH) from the Turku University Foundation. 


\section{References}

1 Barland P, Novikoff A B, Hamerman D. Electron microscopy of the human synovial membrane. J Cell Biol 1962; 14: 207-20.

2 Sokoloff L. Pathology of rheumatoid arthritis and allied disorders. In: McCarty D J. ed. Arthritis and allied conditions. 9th ed. Philadelphia: Lea and Febiger. 1979: 429-48.

3 Janossy G, Panayi G, Duke O, Bofill M. Poulter L W. Goldstein G. Rheumatoid arthritis: a disease of T-lymphocyte/ macrophage immunoregulation. Lancet 1981: ii: 839-42.

4 Meijer C J L M. de Graaff-Reitsma C B. Lafeber G J M. Cats A. In situ localization of lymphocyte subsets in svnovial membranes of patients with rheumatoid arthritis with monoclonal antibodies. J Rheumatol 1982: 9: 359-65.

5 Førre $\varnothing$. Thoen J. Lea T. et al. In situ characterization of mononuclear cells in rheumatoid tissues. using monoclonal antibodies. No reduction of T8-positive cells or augmentation in T4-positive cells. Scand J Immunol 1982: 16: 315-9.

6 Burmester G R. Dimitriu-Bona A. Waters S J. Winchester R J. Identification of three major svnovial lining cell populations by monoclonal antibodies directed to la antigens and antigens associated with monocytes/macrophages and fibroblasts. Scand J Immunol 1983: 17: 69-82.

7 Dayer J-M. Krane S M. Russell R G G. Robinson D R. Production of collagenase and prostaglandins by isolated adherent rheumatoid synovial cells. Proc Natl Acad Sci USA 1976: 73: 945-9.

8 Woolley D E. Brinckerhoff C E. Mainardi C L. Vater C A. Evanson J M. Harris E D Jr. Collagenase production by rheumatoid synovial cells: morphological and immunohistochemical studies of the dendritic cell. Ann Rheum Dis 1979: 38: $262-70$.

9 Winchester R J. Burmester G R. Demonstration of la antigens on certain dendritic cells and on a novel elongate cell found in human synovial tissue. Scand J Immunol 1981; 14: 439-44.

10 Panayi G S. Wooley P. Batchelor J R. Genetic basis of rheumatoid disease: HLA antigens, disease manifestations and toxic reactions to drugs. $\mathrm{Br}$ Med J 1978: ii: 1326-8.

$11 D^{\prime}$ Onofrio $C$. In vitro differentiation of human monocvtes into mature macrophages during long-term cultures. Immunobiology 1983: 164: 13-22.

12 Zuckerman S H. Ackerman S K. Douglas S D. Long-term human peripheral blood monocyte cultures: establishment. metabolism and morphology of primary human monocytemacrophage cell cultures. Immunology 1979; 38: 401-11.

13 Tew J G. Thorbecke G J. Steinman R M. Dendritic cells in the immune response: characteristics and recommended nomenclature. J Reticuloendothelial Soc 1982: 31: 371-80).
14 Kahn H J. Marks A. Thom H. Baumal R. Role of antibody to S100 protein in diagnostic pathology. Am J Clin Pathol 1983. 79: $341-7$.

15 Takahashi K. Yamaguchi H. Ishizeki J. Nakajima T. Nakazatos Y. Immunohistochemical and immunoelectron microscopico localization of S-100 protein in the interdigitating reticulum cells of the human lymph node. Virchows Arch /Cell Pathol] 1981: 37: $125-35$.

16 Burmester G R. Schnecberger J. Jahn B. Gramatzki M. Zacher尺 J. Kalden J R. Rheumatoid non-lymphoid synovial cells and then induction of mixed leukocvte reactions. Rhetumatol Int 1984: 4:D $31-7$

17 Hendler P L, Lavoic P E. Werb Z. Chan J. Scaman W E. Human synovial dendritic cells. Direct observation of transition $\vec{\omega}$ to fibroblasts. J Rheumatol 1985: 12: 6601-4.

18 Heino J. Viander M. Kouri T. Morphologic alterations ind cultured human synovial fibroblasts induced by blood mononuclear cells. Exp Cell Biol 1984: 52: 347-54.

19 Baker D G. Daver J-M. Roclke M. Schumacher H R. Krane So M. Rheumatoid synovial cell morphologic changes induced by at mononuclear cell factor in culture. Arthritis Rheum 1983: 26: $8-14$

20) Heino J. Connective tissue components in sunovial fibroblasto cultures exposed to interleukin 1 and prostaglandin E, Virchows Arch /Cell Patholl 1986: 50: 313-20.

21 Pober J S. Collins T. Gimbrone M A Jr. et al. Lymphocvtes recognize human vascular endothelial and dermal fibroblast la antigens induced by recombinant immune interferon. Nature 1983: 305: 726-9.

22 Amento E P. Bhan A K. Kranc S M. Effects of interferon amd $\overrightarrow{0}$ mononuclear eell factor on adherent rheumatoid svnovial cu: alterations of la expression and collagen sunthesis |Abstriat. Arthritis Rheum 1984: 27: S23.

23 Ruoslahti E. Vaheri A. Novel human serum protein fromlo fibroblast plasma membrane. Nature 1974: 248: 7901-1.

24 Alitalo K. Hovi T. Vaheri A. Fibronectin is produced by humano macrophages. J Exp Med 1980: 151: 6(2)-13.

25 Matsubara T. Spycher M A. Rüttner J R. Fehr K. The ultrastructural localization of fibronectin in the lining laver of rheumatoid arthritis svnovium: the svnthesis of fibronectin by응 type B lining cells. Rheumatol Int 1983: 3: 75-9.

26 Mapp P I. Revell P A. Fibronectin production by svnovial intimal cells. Rheumatol Int 1985: 5: 229-37.

27 Shiozawa S. Shiozawa K. Fujita T. Presence of HLA-DR antigen on synovial type $A$ and $B$ cells: an immunoclectron microscopic study in rheumatoid arthritis. osteoarthritis and normal traumatic joints. Immunology 1983: 50: 587-94 